\title{
Polymorphic Extreme Clubfoot Deformities in Newborns and their Total Correction by Polyarticular, Poly-Axial, Inclusive Manipulation and Serial Castings-(Evidence Based Patiala Technique)
}

ISSN: 2576-8875

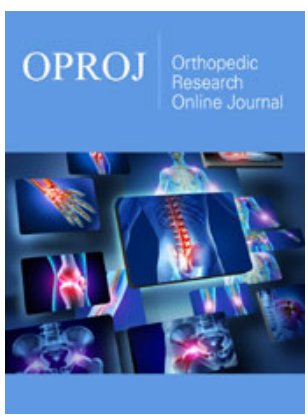

*Corresponding author: Mittal RL, Director/ Consultant, Mittal Ortho Centre 97 New Lal Babh Colony, Patiala $(\mathrm{Pb}) 47001$ INDIA, Emeritus Professor, Ortho GOMCO Patiala

Submission: 留 December 21, 2020

Published: 漈January 18, 2021

Volume 7 - Issue 5

How to cite this article: Mittal RL. Polymorphic Extreme Clubfoot Deformities in Newborns and Thier Total Correction by Polyarticular, Poly-Axial, Inclusive Manipulation and Serial Castings(Evidence Based Patiala Technique). Ortho Res Online J. 7(5). OPROJ. 000675. 2021. DOI: 10.31031/OPROJ.2021.07.000675

Copyright@: Mittal RL, This article is distributed under the terms of the Creative Commons Attribution 4.0 International License, which permits unrestricted use and redistribution provided that the original author and source are credited.

\section{Mittal RL*}

Director/ Consultant, Mittal Ortho Centre 97 New Lal Babh Colony, Patiala (Pb) 47001 INDIA, Emeritus Professor, Ortho GOMCO Patiala

\begin{abstract}
Purpose: Author published in International Orthopaedics (SICOT), a new surgical concept, treating 95\% relapses/under-corrections in trimorphic extreme clubfoot deformities [1]. Present innovative, comprehensive, serial manipulation and casting technique in newborns, being successful in preventing these failures, is a complement to that. This new casting technique is a continuation of this research in to 4th phase. Clubfoot is a polymorphic deformity (trimorphic term evolved just for convenience of treatment in SICOT publication). Extreme deformities are very common at birth, given the above quoted relapse/ under-corrections rate. With poly-axial movements at every foot joint, clubfoot deformity is a cumulative polyarticular presentation and each one is different.
\end{abstract}

Material and Methods: Sixteen patients with 21 extreme deformities have been treated till now. An allinclusive maneuver, reversing all deforming components at each joint, from ankle to toes, is constantly maintained while the foot is being fixed in a well molded below knee cast. This cast, when set after partial correction of the deformity by an all-inclusive maneuver, is further extended as a hood on the front and sides of knee, leaving posterior aspect free. The completed cast has been named as BK Hoody cast or Cobra Hood cast due to its resemblance with it (Figure 2).

Results and Conclusions: The technique is well conceived, evidence based, with gratifying results in all, at 6 months to 2 years follow up, as given in Table 1. After correction, walking keeps the deformity corrected by static and dynamic influences of weight bearing. It is user friendly, prevents cast slipping out, permitting knee movements, cost effective in avoiding future surgeries from failed treatments saving time and human misery. More work will further consolidate the promising results in these cases.

Keywords: Prefix clubfoot in all: Polymorphic deformity;Total correction in newborns; The new patiala technique; Poly-axial maneuvering and casting in newborns; All-inclusive manipulation and casting; Evidence based new concept; Cobra cast; BK Hoody cast

Abbreviations: LMICs: Low, Middle IncomeCountries; EQ: Equinus; AK: Above Knee, BK: Below Knee; Gr: Grade

\section{Introduction}

Clubfoot is the commonest congenital orthopedic defect, but still remains unsolved. It is a double trouble. Firstly: There are $95 \%$ treatment failures by various contemporary, conservative and surgical techniques in trimorphic extreme deformities (a generic name given, by the author, for scores of confusing terms) [1,2] and secondly: all earlier treatment modalities have their inherent problems. Taking up the most widely used in about 150 countries, Ponseti casting technique, as practiced at University of IOWA hospital, they commented in a 12 years (average), follow up study in 94 severe clubfeet, treated from one week to 6 months age that complete and permanent correction is often difficult. They reported repeated relapses over the years: first relapse in 56\% (53 feet), second in 18\% (17 feet), third in $10 \%$ ( 9 feet) and even fourth time relapse in one patient [3]. Yes, you read it right. Ponseti commented in his manual that this was due to not following his protocol strictly, by his staff and beneficiaries, being laborious.

Ponseti also accepted relapses with increasing age due to heel cord tenotomy, as bones keep growing, but tenotomy scar does not, as opposed to normal tendon. He has specifically accepted failure of his technique in severe and rigid deformities [2,4]. Similar is the case with Kite, French, Illizarov and allied techniques [2,5,6]. Problems faced by large clubfoot 
community and care givers, especially in LMICs, are highlighted in Ponseti's manual [4]. To fulfill the need for an all-inclusive surgical solution for relapses/ under-corrections, including late age uncorrected deformities, author published a comprehensive article in 2018, offering longer, flexible, good looking feet on long term $[1,2]$. However, extreme deformities are quite common at birth given the high relapse rate reported in literature, as above and they are polymorphic in nature right from birth and each one is different [7]. Therefore, the need for, an all-inclusive, conservative treatment was also increasingly realised to prevent mass relapses/ undercorrections and thereby bypass the need for extensive surgeries later.

\section{Deforming elements: Equinus as EQ1-5 and others}

Equinus is commonly believed as a plantar-flexion movement at ankle only, but author described this in 5 hierarchic grades $[1,2]$. The heel and forefoot components of equinus (EQ2 and EQ4) find no mention in clubfoot deformity, besides EQ5, a later age development [1,2]. As discovered by the author [8], there are many other deforming elements in distal foot quite often, like varus, hyperextended and/or flexed toe joints etc. They are present at birth varyingly and get modified with increasing age by multifactorial static and dynamic influences. Increasing age also leads to, innumerable, early and delayed complications. All details are beyond the scope of this article and can be read in author's latest comprehensive publications of 2020 [6-8]. Being a polymorphic deformity, (Figure 1a-1q) each case will need individual clinical assessment for deformations at various locations. At birth, conservative is the best way to prevent under-corrections and relapses. Present technique is more user friendly, highly cost effective, lessening long term worries by avoiding future surgeries, improving psycho-physico-socio-economic status.

\section{Material and Methods}

Twenty one feet in 16 patients were treated by this technique. There were five bilateral, nine right and two left feet; $12 \mathrm{M}$ : $4 \mathrm{~F}$, seven patients of Gr1 (seven feet), five of Gr2 (eight feet) and four of Gr3 (six feet), with other details given in Table 1. The basic principle is an all-inclusive maneuver to reverse all the deforming components at all the joints, for total correction of deformity. None of the contemporary conservative methods of treatment have taken into consideration the polymorphism of clubfoot, from ankle to toes and hence are not inclusive treatments [3-6]. Author innovated this highly acceptable, evidence based, all- inclusive, manipulation and casting technique, to prevent under-corrections and relapses. For all extreme deformities, with or without additional deforming features, this is an exclusive technique, compared to contemporary techniques. Mild and moderate deformities, too, will be corrected. Costing: Working out the specific cost of this treatment at Patiala, India, average 12 casts will cost 1500/- rupees per case i.e., 20 USD in a Government hospital in India, where outpatients' treatment is free for all. If correction occurs early before the walking age, a low cost, custom made brace, created from a well molded posterior plaster slab, with foot in slightly overcorrected position, is given, till the child starts walking, to prevent recurrence. If the patient is able to walk, child can even walk about in the cast with fully corrected deformity, to be replaced with another cast as required and author has done it also (Figure 3a-3f). This is replaced by another one, if required. Motorcycle is a common mode of transport in India. Hence, average expenses, including logistics of transport, may be only INR 3000/ per case i.e., USD 40/-, very low indeed.

Table 1: Grading as in SICOT 2018 [1].

\begin{tabular}{|c|c|c|c|c|c|}
\hline S.No & $\begin{array}{l}\text { Name, Age, Sex, } \\
\text { Side }\end{array}$ & Grade & $\begin{array}{l}\text { Manipulation, Casting } \\
\text { Frequency }\end{array}$ & No of Casts & Result, F.U \\
\hline 1 & MS, 4mths, M, Rt & Gr1 & fortnightly casts & eight & Good at $1 y$ \\
\hline 2 & VS, 6mths, M, Rt & Gr1 & fortnightly casts & eight casts & Good at $1 \mathrm{Y}$ \\
\hline 3 & I, 20D, M, BL & Gr2 & $\begin{array}{l}\text { fortnightly casts } 6 \\
\text { Mthly } 6\end{array}$ & $\begin{array}{l}12 \text { casts, } \\
\text { Then POP splint }\end{array}$ & Good at $1 Y$ \\
\hline 4 & A, 20D, F, Lt & Gr1 & Fortnightly casts & $\begin{array}{c}8 \text { casts. } \\
\text { Then POP splint }\end{array}$ & Good at $1 Y$ \\
\hline 5 & U, 11/2Mths, M, Rt & Gr2 & $\begin{array}{l}\text { Fortnightly casts } 6 \text {, } \\
\text { then mthly } 6\end{array}$ & 12 casts & Good at $11 / 2 \mathrm{Y}$ \\
\hline 6 & MG $21 / 2$ mths, M, Rt & Gr2 & $\begin{array}{l}\text { Fortnightly } 6 \\
\text { Mthly } 4\end{array}$ & 10 casts & Good at $2 \mathrm{y}$ \\
\hline 7 & SK, 311/2Mths, F, BL & Gr2 & $\begin{array}{l}\text { Fortnightly } 6 \\
\text { Mthly } 4\end{array}$ & 10 casts & Good at 2y \\
\hline 8 & JK 1Mth, F, BL & Gr2 & $\begin{array}{l}\text { Fortnightly } 6 \\
\text { Mthly } 6\end{array}$ & 12 casts & Good 2Y \\
\hline 9 & $\begin{array}{l}\text { A } 10 \mathrm{D} \text { M, BL } \\
\text { (Figure 4) }\end{array}$ & Gr3 & $\begin{array}{c}\text { Weekly } 4 \text { Fortnightly } 6 \\
\text { Mthly } 6\end{array}$ & $\begin{array}{l}16 \text { casts } \\
\text { POP splints }\end{array}$ & Good 1Y \\
\hline 10 & $\mathrm{~J} 1 \mathrm{mth}, \mathrm{F}, \mathrm{Lt}$ & Gr3 & $\begin{array}{c}\text { Weekly } 4 \text {, } \\
\text { Fortnightly } 6 \text {, mthly } 6\end{array}$ & $\begin{array}{l}16 \text { casts } \\
\text { POP splint }\end{array}$ & Good 8 months \\
\hline 11 & $\begin{array}{l}\text { GKS, 3wks, M, BL } \\
\text { (Figure 3) }\end{array}$ & Gr3 & $\begin{array}{l}\text { Weekly } 4 \text {, fortnightly } 6 \text {, } \\
\text { mthly } 6\end{array}$ & 16 casts & Good 6 mths \\
\hline
\end{tabular}




\begin{tabular}{|c|c|c|c|c|c|}
\hline 12 & GJS, 8mths, M Rt & Gr1 & Fortnightly & 8 casts & Good at 6 months \\
\hline 13 & KPS, $1 \frac{1}{2} 2 \mathrm{mths}, \mathrm{M}, \mathrm{Rt}$ & Gr1 & Fortnightly & $\begin{array}{c}8 \text { casts. } \\
\text { Then Pop splints }\end{array}$ & Good at $1 Y$ \\
\hline 14 & H, 3wks, M, Rt & Gr1 & Fortnightly & $\begin{array}{c}8 \text { casts. } \\
\text { Pop splint }\end{array}$ & $\begin{array}{l}\text { Good child } \\
\text { walking }\end{array}$ \\
\hline 15 & $\mathrm{~N}, 9 \mathrm{mths}, \mathrm{M}, \mathrm{Rt}$ & Gr1 & Fortnightly & 8 casts & Good at $6 \mathrm{mths}$ \\
\hline 16 & $\begin{array}{l}\text { SS, 3wks, M, Rt } \\
\text { (Figure 5) }\end{array}$ & Gr3 & 7-10 days & 10 casts & $\begin{array}{c}\text { Good correction } \\
\text { continuing tt }\end{array}$ \\
\hline
\end{tabular}

Abbreviations: F: Female; FU: follow Up; Gr: Grade; WKS: Weeks; M: Male; POP: Plaster of Paris; Rt: Right; Lt: Left; S.No: Serial Number; tt: Treatment; Y: Year

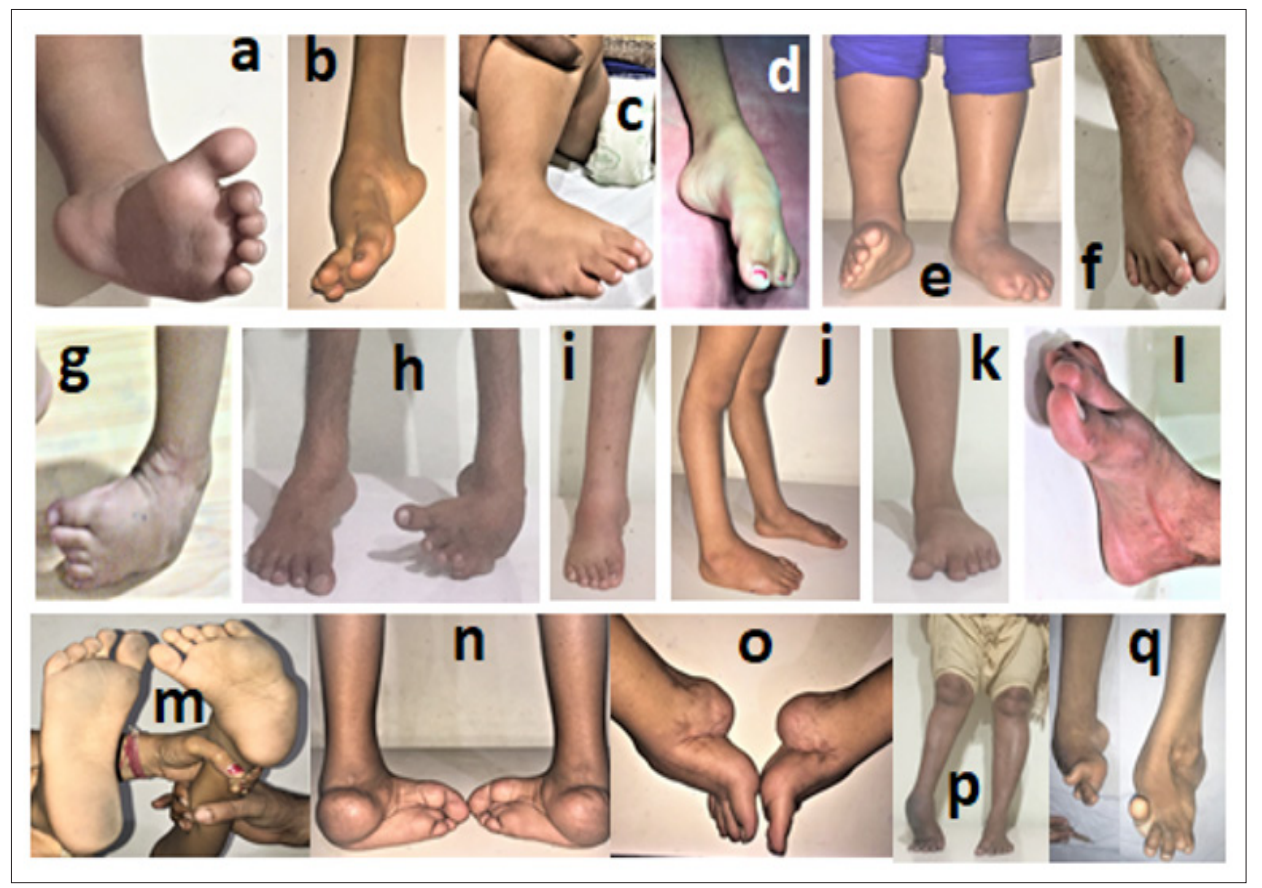

Figure 1a-q: Polymorphism in clubfoot, each different.

\section{Starting the treatment}

It must be started as soon after birth as possible and pursued till the walking age, 10-12 months or a little later for best results. However, late presentations, before walking age, are also treated by this technique. Weight bearing during walking with plantigrade foot, keeps the deformity corrected by the static and dynamic influences and prevents relapse. In very rigid deformities if the deformity still remains under-corrected, at one year, surgery is indicated. Each case is assessed for all deforming components in the foot, before starting treatment.

\section{Protocol for first three weeks after birth}

Only gentle repeated manipulations, towards correction should be taught and started by the parents, thrice a day, adequate enough till the child starts crying. Backside of the heel should be held between thumb and index of one hand and with other hand distal foot is abducted and everted toward correction, with a counter force at $5^{\text {th }}$ metatarsal base and retained in that position for 10 seconds, then relax for 5 seconds. This will take $2 \frac{1}{2} 2$ minutes for 10 repetitions each time.

\section{Plaster casting treatment}

This is started after 3 weeks, when the infant gets accustomed. Manipulation is a comprehensive maneuver, acting at every joint from ankle to toes, depending upon the examination finding. It should partially undo all the deformities at each joint every time, as tolerated by the child. POP cast is applied in two parts. First part is a BK plaster cast, which is applied while maneuvering and molding simultaneously, because BK cast is smaller, more focused and easily manageable for continuous poly-articular corrective force. Second part casting: After the first cast sets, it is extended above as a $\mathrm{AK}$ hood, which is tied like a turban, over the dome and sides of flexed knee, in continuity with the front of BK cast. The completed cast has been named as BK Hoody or BKH cast or a cobra hood cast due to its resemblance to it (Figure 2). For right foot deformity: First part-An assistant holds the condylar part of internally rotated and extended thigh by left hand, with his straight thumb along lateral side over fibular head to prevent constriction of cast there and holding the toes with right hand from great toe side, straightening the foot as the child tolerates. 


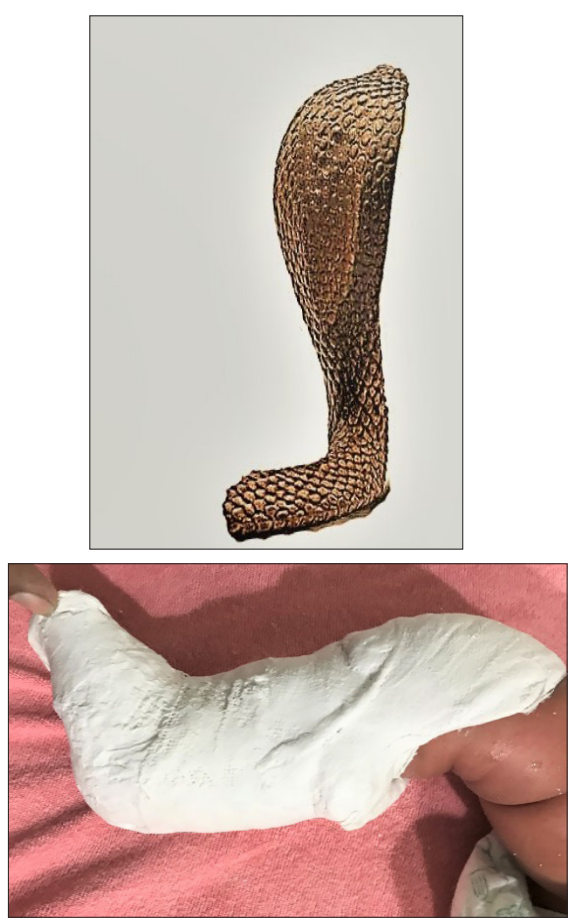

Figure 2: Cobra hood image \& Below Knee Hoody cast BKH (Cobra hood) cast.

Adequate cotton padding is applied over the foot and leg, covering toes. Warm water wet 3" or 4" POP bandage is wrapped around the foot and leg, remaining about an inch distal to flexion crease of knee behind. Composite foot deformity is now corrected, by a comprehensive maneuver, acting at every joint, from toes to ankle, correcting all deforming elements and molding the cast, around foot/ankle/leg contours. The heel equinus and talo-navicular dislocation are corrected by pressing talar head from dorso-lateral side towards medial side and anterior end of calcaneum dorsally, at the appropriate places to bring down the heel, restoring the decreased talo-calcanean angle and index [9]. When the cast is almost set, the assistant takes out his thumb from proximal side, for molding that part of the cast too (Figure 3). The whole deformity is corrected, within toleration limits of the child and maintaining good arterial circulation in the toes.

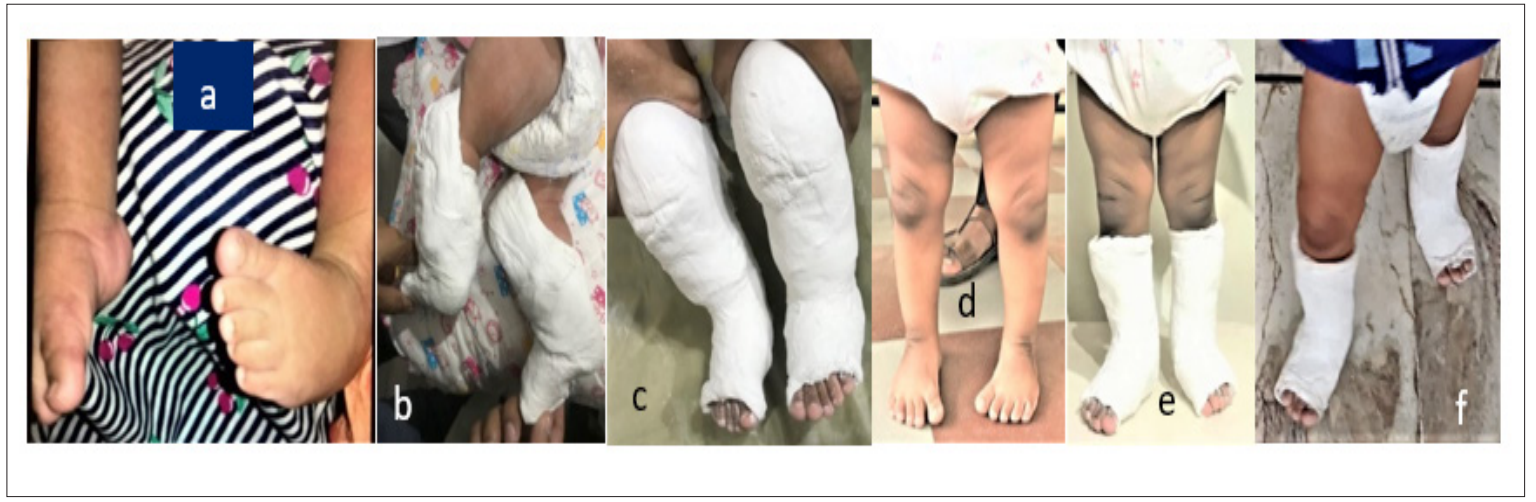

Figure 3: GKS a: Gr3 B/L; b,c: BKH cast from side and front; d-f: residual varus, corrected for walking BK cast and right step forward for walking.

The ends of the cast are rounded. Second part- This part of cast is an extension of leg cast in front and sides of a $90^{\circ}$ flexed knee, like a hood, leaving the back of knee free for ventilation and active knee flexion. Assistant holds plastered foot with right hand and thigh close to groin with left hand, with knee flexed at $90^{\circ}$. Soft cotton is applied to the thigh and knee, overlapping the proximal end of cast. Plaster bandage is applied like tying a turban with 4 to 6 circular turns around the knee, covering the front of leg cast, with a couple of up and down overlapping layers on the front of knee (Figure 4). The leg portion of BK hoody cast is fixed with one or two circular turns of POP bandage, leaving the back of knee crease free. Remove the excess cotton from behind and mold the hood around the bony contours and rounding the edges, while the POP sets. Child is more comfortable in this cast hood, enabling knee flexion and ventilation. For the left foot casting, assistant changes his hands. 


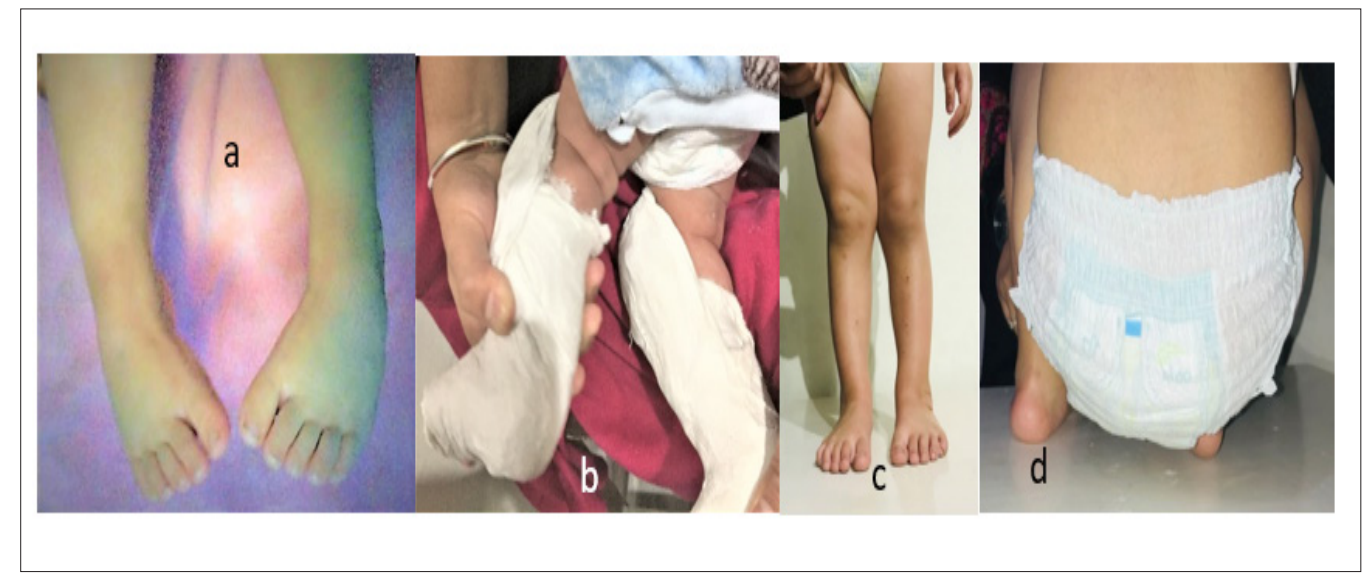

Figure 4: Prematue 2mths underweight, casts started after 2 months, first wkly:
a. Gr3 Rt foot,
b. BKHoody cast, free behind,
c. after 3 mths,
d. Occult equinus also corrected.

Removal of cast, an easy way: parents remove the cast, previous evening by repeatedly pouring warm water over the cast, keeping the leg over a small tub and cast will easily get unwrapped. Foot and leg are washed. The next morning, they come for a repeat cast. Number and schedule of casts: This cannot be fixed, because the deformity is polymorphic, from mild to the most severe and rigid. Presenting age is also variable from birth to a few months and repeat visits may sometimes be irregular (Figure 5). If patient comes late and deformity is very severe; more weekly casts are given. A tentative regimen in very severe/rigid extreme deformity, at 3 weeks age, could be 4 weekly casts, changing to fortnightly, every 3 weeks and monthly casts till walking age. The best suitable regimen is worked out by the treating surgeon with one's experience. In the author's experience, this has varied from 8 to 16 casts. Last 2 casts are below knee at the walking age and the child is encouraged to stand and walk in the cast and then free walking in the normal shoes. However, sometimes with slight adduction with or without inversion deformity; shoes with inner border straight or slightly convex, with or without raised outer border by $1 / 6^{\text {th }}$ of an inch are advised, for 6 months to one year. In such cases, author has also tried reversing the shoes i.e right shoe for the left foot and vice versa and this also works in bilateral cases with no extra cost. If the deformity gets corrected early before the walking age, a custom-fit, low cost, single or double posterior plaster mold (in bilateral cases) in overcorrected position are advised, till the child starts walking.

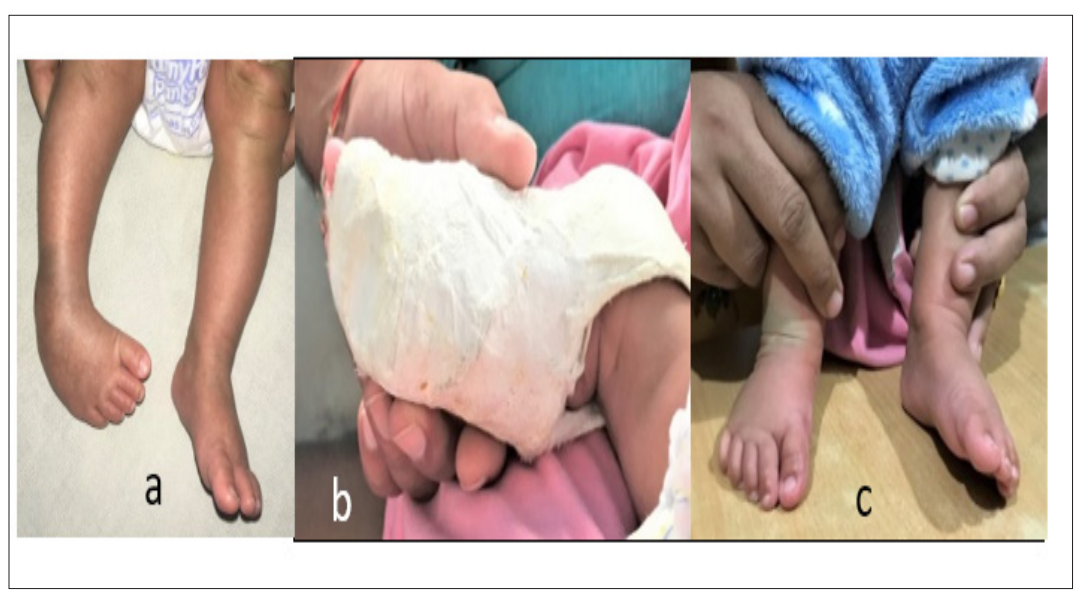

Figure 5: Premature born at 7 months and casting started after 2 months:
a. Gr3 deformity,
b. side view BKhoody (cobra) cast,
c. correction after 3 months, still continuing to correct equinus. 


\section{Results}

This technique will surely prevent relapses and undercorrections, reported in literature, if this treatment is given in infancy. Author has treated 21 feet of extreme deformities by this technique, in 16 patients, during the last about 4 years, with uniformly good results, as below in Table 1 .

\section{Discussion}

One more lock has been opened, amongst many unlocked earlier in polymorphic clubfoot deformities and that too with a Master Key. It has been possible by evidence based, unified concept of polyarticular, poly-axial inclusive manipulation and casting technique. Being the organ of locomotion, feet are essential for earning livelihood. Good functioning feet are also required for sports, lovely high heel foot wears, dancing and in fact, every field of human activity. In India, we bow to the feet of Deities, teachers and elders; as a symbol of humility. Without good functioning feet, life can only be one with a high psycho-physico-socio-economic handicap. Therefore, it is imperative to identify the deformities in the cradle and treat them conservatively with an improved technique for preventing relapses and under-corrections.

Human foot is a nature's marvel, requiring coupled movements, at all its 30 joints, in different axes and planes for its functional needs in different terrains. Clubfoot deformity is polymorphic in nature, with unlimited combinations even at birth. The term, trimorphic, was evolved only for convenient planning of surgical treatment [1]. Suffice it to say that each case is different in external morphology, inside anatomy and radiological picture due to complex, coupled movements, getting further modified after birth by static and dynamic factors. With all mal-positioned joints, the bones too become mis-shapen. The deformity is not only at hindfoot and mid-foot, as is commonly believed, but quite often seen in the forefoot also (in toes) in varied formats. Extreme deformities i.e., severe and rigid are very common at birth, given the $95 \%$ relapse rate and under-corrections reported in literature with contemporary techniques $[1,2]$. If we want good correction in every case, they do need a different conservative approach than mild and moderate cases to prevent relapses and under-corrections from contemporary techniques as reported in literature. Evolution of this technique is based on the polyarticular/polymorphic pathoanatomy of the extreme deformities, prevalent at birth, as stated above. "Prevention is better than cure" is a well-known saying. The new casting technique, based on patho-anatomical evidence, is a definite improvement on contemporary techniques, being comprehensive and inclusive. The same size of shoes will fit all, provided it is adaptable. The technique is highly cost effective, requiring much less effort, with high acceptability, preventing under-corrections and relapses.

Application of the cast in 2 parts with second part, adding a knee hood, has been evolved for its multiple benefits:

a. prevents the partial or complete slipping out of cast in severe deformities, more so in chubby infants; b. it is lighter;

c. it is functional, permitting knee movements;

d. Growth of limb is not hampered due to months of immobilization;

e. Maintains ventilation for comfort, in hot and humid weather;

f. The first part as a BK cast is better manageable by hands, being smaller, assuring better control for comprehensive, inclusive maneuver, which will reverse all deforming elements around foot and better molding around bony contours of foot/ankle complex and

g. In part 2, the hood on the knee, provides firm anchorage of BK cast to femoral condyles, preventing slipping out, permitting partial movements for comfort and growth. Author feels that all aims of evolving the technique have been effectively achieved. Removal of the cast is also easy and comfortable, by wetting the cast and un-wrapping it.

The casting technique reverses the deformities at all the joints towards normalcy, by coupled, polyarticular, distraction and compressive forces. The soft bones of infants get molded, restoring the articular surfaces towards normalcy in a gradual way. After correction, similar forces of normal weight bearing keep the deformity corrected, by natural static and dynamic mechanics and modified shoes, further supplement these forces.

\section{Conclusion}

It is safe vouched that the technique is a comprehensive and inclusive, polyarticular from ankle to toes, correcting at the osteoarticular level by differential compressive and distracting forces, for normalization of foot. Clubfoot opens out from the crouched position, just like opening out of fist. The long term results are also expected to remain good.

\section{References}

1. Mittal RL (2018) Trimorphic extreme clubfoot deformities and their management by triple surgical skin expanders-DOLAR, DOLARZ and DOLARZ-E (evidence based mega corrections without arthrodesis). Int Orthop 42(6): 1297-1306.

2. Mittal RL (2018) CLUBFOOT - A comprehensive approach (past, present and future), (1 $1^{\text {st }}$ edn), Taylor and Francis (CRS Press), USA, p. 98.

3. Ponseti IV, Smoley EN (2009) The classic congenital club foot: The results of treatment. Clin Orthop Relat Res 467(5): 1133-1145.

4. Staheli L, Ignacio P (2009) Clubfoot: Ponseti management manual ( $3^{\text {rd }}$ edn), USA, p. 32.

5. Kite JH (1972) Non-operative treatment of congenital clubfoot. Clin Orthop Relat Res 84: 29-38.

6. Bensahel H, Guillaume A, Czukonyi Z, Desgrippes Y (1990) Results of physical therapy for idiopathic clubfoot: A long-term follow-up study. J Ped Orthop 10(2): 189-192.

7. Mittal RL (2019) Feet also need cosmetic/plastic surgery for good looks (A New Perspective) world's first, graded, mega skin expansion by fusion 4-in-1, correcting, all-inclusive, extreme clubfoot deformities-a game changer. J Dermatol \& Skin Sci 1(1): 8-17. 
8. Mittal RL (2020) Each clubfoot is different, mother of all clubfoot innovations (an incredible unity in diversity, with cure-all, fusion 4-in-1 surgical concept). Ortho Res Online J 7(1): 689-697.
9. Beatson T R, Pearson J R (1966) A method of assessing correction in club feet. J Bone Joint Surg Br 48(1): 40-50.

For possible submissions Click below:

Submit Article 